\title{
Stage IV Uterine Corpus Cancer AJCC v7
}

National Cancer Institute

\section{Source}

National Cancer Institute. Stage IV Uterine Corpus Cancer A/CC v7. NCI Thesaurus. Code C89636.

Stage IV includes: IVA: (T4, Any N, M0); IVB: (Any T, Any N, M1). T4: Tumor invades bladder mucosa and/or bowel mucosa (bullous edema is not sufficient to classify a tumor as T4). M0: No distant metastasis. M1: Distant metastasis (includes metastasis to inguinal lymph nodes, intraperitoneal disease, or lung, liver, or bone. It excludes metastasis to para-aortic lymph nodes, vagina, pelvic serosa, or adnexa). This staging applies to carcinomas and carcinosarcomas. (AJCC 7th ed.) 